Supporting information

\title{
Oral GLP1 Gene Delivery by an Antibody-Guided Nanomaterial to Treat Type 2 Diabetes Mellitus
}

\author{
Mohammad Nazmul Hasan ${ }^{1}$, Yong Hwa Hwang ${ }^{2}$, Jeong Man An ${ }^{3}$, S. M. Shatil \\ Shahriar ${ }^{3}$, Sungpil Cho ${ }^{2,4^{*}}$, Yong-kyu Lee ${ }^{1,2,3,4 *}$ \\ ${ }^{1}$ Department of Green Bioengineering, Korea National University of Transportation, Chungju \\ 27469, Republic of Korea \\ ${ }^{2}$ KB BioMed Inc., Chungju 27469, Republic of Korea \\ ${ }^{3}$ Department of Chemical and Biological Engineering, Korea National University of \\ Transportation, Chungju 27469, Republic of Korea \\ ${ }^{4} 4 \mathrm{D}$ Biomaterials Center, Korea National University of Transportation, Jeungpyeong 27909, \\ Republic of Korea
}

Corresponding authors: *S. Cho: $\underline{\text { sungpilcho74@ut.ac.kr, *Y. Lee: leeyk@ut.ac.kr }}$ 


\section{EtBr displacement assay}

The EtBr displacement assay determined the degree of DNA (GLP1 gene) condensation. The binding of nanocarrier with DNA would displace the intercalated $\mathrm{EtBr}$ and subsequently quench the fluorescence caused by the EtBr-DNA complex. The assay was carried out in 96-well plate in $10 \%(\mathrm{w} / \mathrm{v})$ glucose and 10mM HEPES buffer $(\mathrm{pH} 7.4)$. DNA $(10 \mu \mathrm{g} / \mathrm{mL})$ and Fc-carrier were dissolved separately in $1 \mathrm{~mL}$ buffer, mixed in case of complex formation for 30 mins and later $10 \mu \mathrm{L}$ of $\operatorname{EtBr}(0.1 \mathrm{mg} / \mathrm{mL})$ was adeed to the complex solution. The samples were incubated for $30 \mathrm{mins}$ in the dark at room temperature. Fluorescence was read in a microplate reader at excitation and emission wavelength of 520 and $600 \mathrm{~nm}$, respectively. The relative fluorescence values are evaluated by the following equation: $F_{r}=\left(F_{o b s}-F_{e}\right) X 100 /\left(F_{0}-F_{e}\right)$, where $F_{r}$ is the relative fluorescence, $\mathrm{F}_{\mathrm{obs}}$ is the measured fluorescence, $\mathrm{F}_{\mathrm{e}}$ is the fluorescence of $\mathrm{EtBr}$ in the absence of DNA, and $\mathrm{F}_{0}$ is the initial fluorescence of naked DNA.

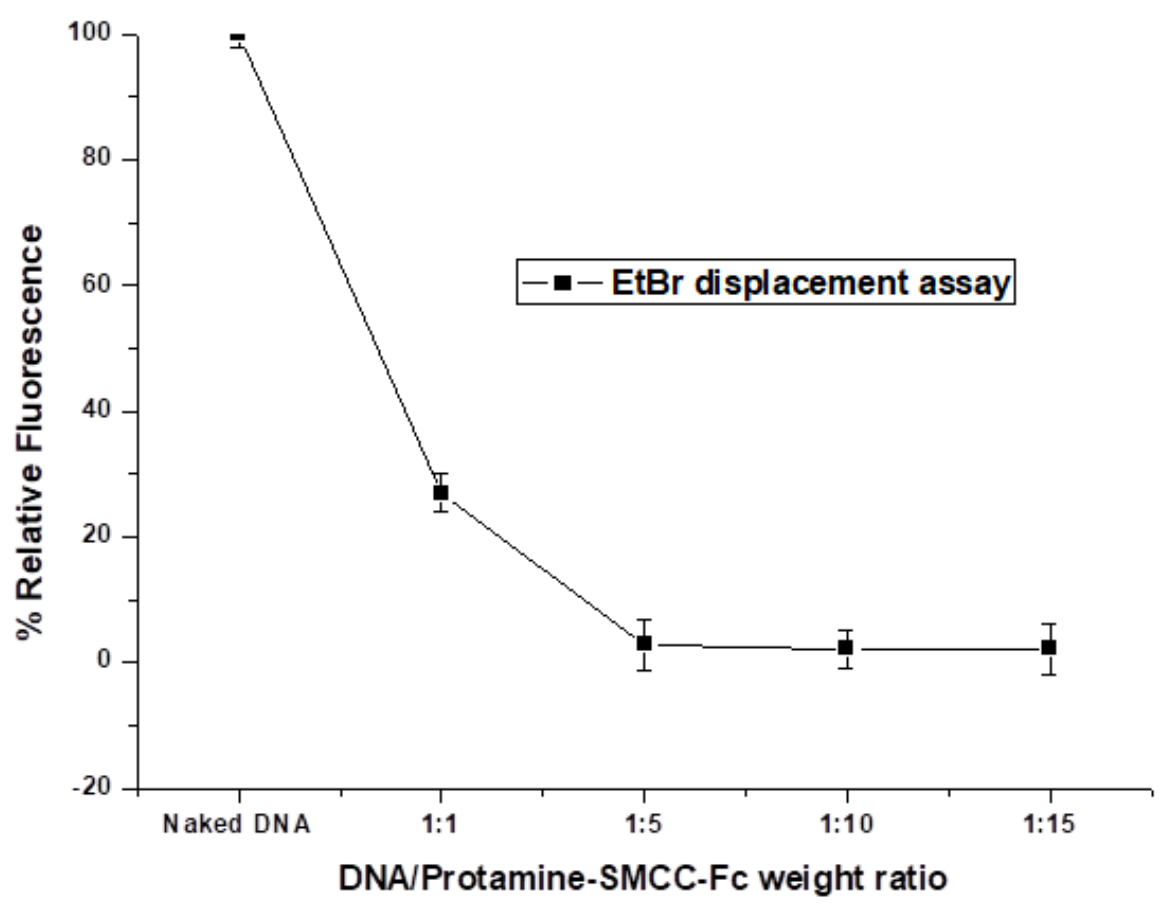

Figure S1. Ethidium Bromide (EtBr) displacement assay. GLP-1 gene started to be condensed from a 1:5 ratio and stabilized at a 1:15 ratio. The values are given as the mean \pm SD of triplicates. 


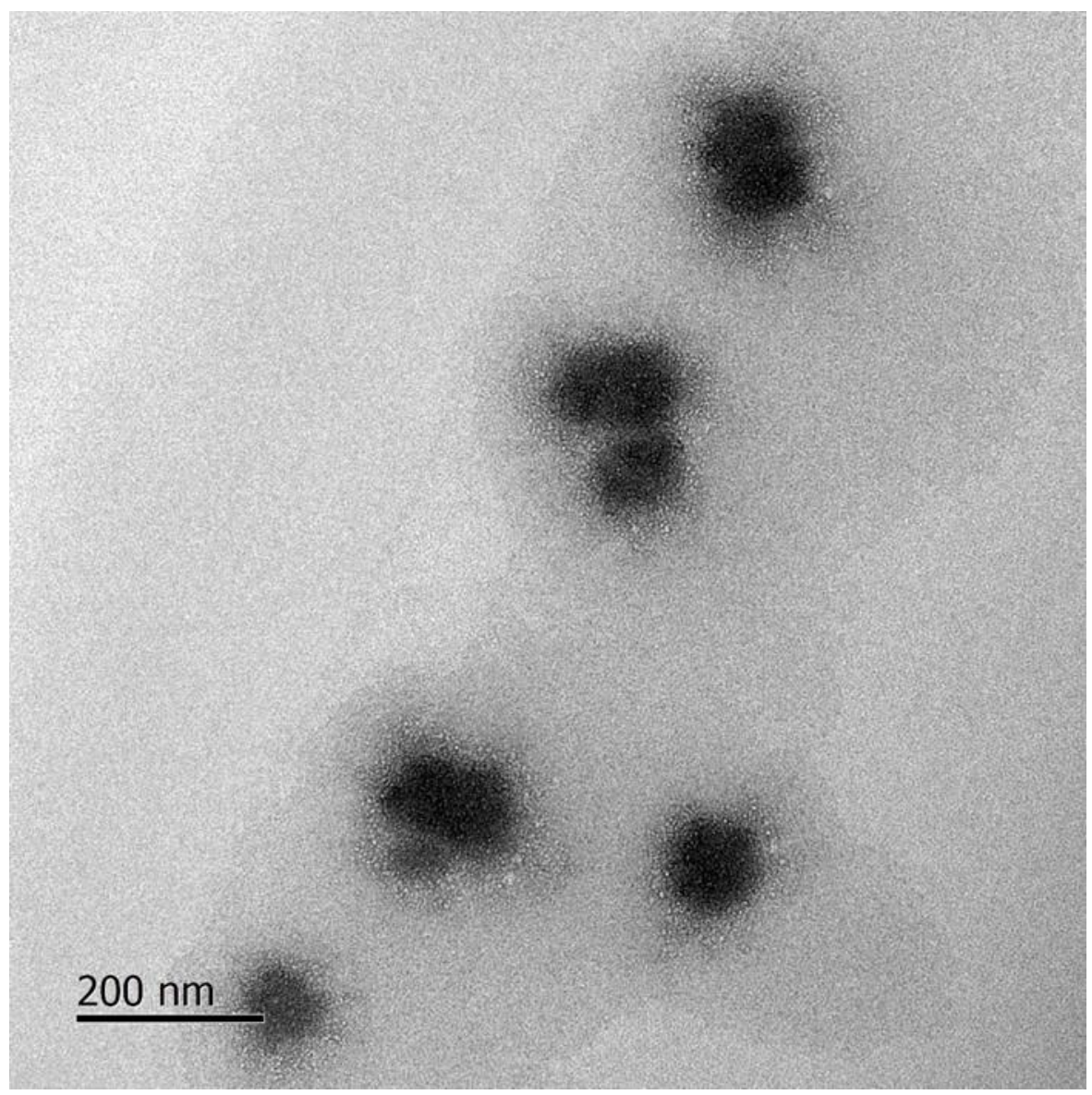

Figure S2. Transmission Electron Microscopy (TEM, JEM-3011 HR, JEOL Ltd.,Japan) image of GLP1/protamine-SMCC-Fc complex.(Scale bar: 200nm) 

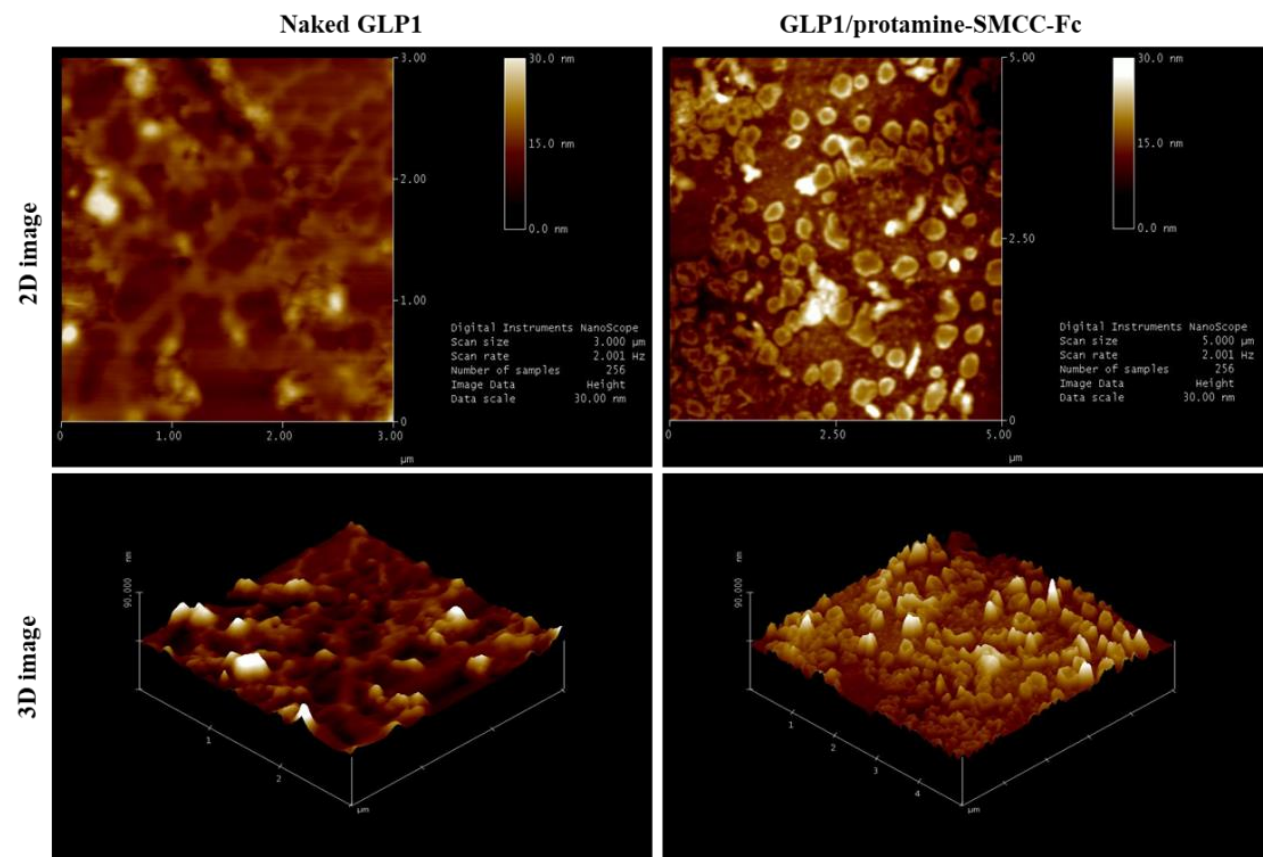

Figure S3. Morphology analysis of the pDNA(GLP-1)/Protamine-SMCC-Fc nanocomplex by Atomic Force Microscopy(AFM), (Digital Instrument Nanoscope IV, Veeco, Santa Barbara, CA) 


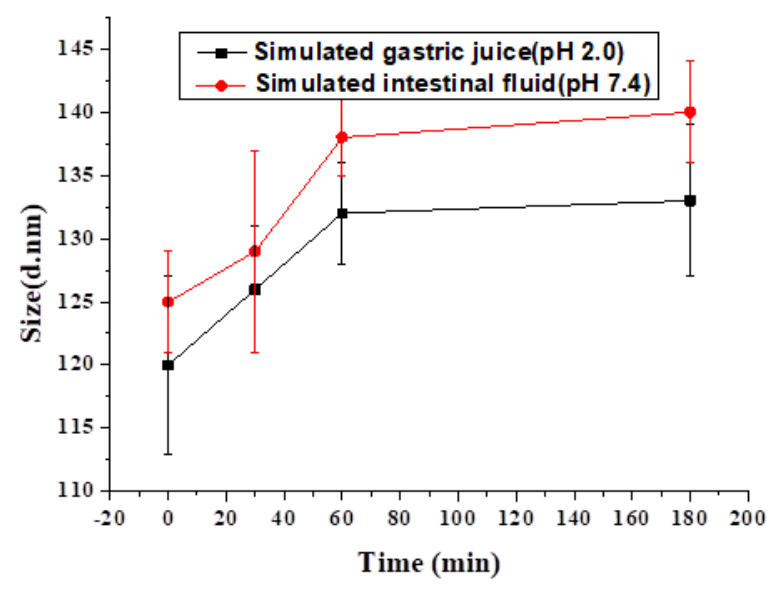

Figure S4. Stability of the GLP1/protamine-SMCC-Fc (1:15) nanocomplex. The stability analysis of the nanocomplex was performed in simulated gastric juice $(\mathrm{pH} 2.0)$ and simulated intestinal fluid $(\mathrm{pH} 7.4)$ and the size was measured by DLS. Simulated gastric juice was prepared by adding pepsin to $0.5 \%(\mathrm{w} / \mathrm{v})$ saline solution to the concentration of $3 \mathrm{~g} / \mathrm{L}$ and the $\mathrm{pH}$ was adjusted to 2.0 using $0.1 \mathrm{~N} \mathrm{HCl}$. Simulated small intestinal fluid was prepared by adding pancreatin to $0.5 \%(\mathrm{w} / \mathrm{v})$ saline solution to the concentration of $1 \mathrm{~g} / \mathrm{L}$ and the $\mathrm{pH}$ was adjusted to 7.4 with $0.1 \mathrm{~N} \mathrm{NaOH}$. 


\section{Cumulative release of pGLP1}

The pGLP1 was mixed with the nanocarrier (1:15 w/w ratio) and incubated in room temperature $\left(25^{\circ} \mathrm{C}\right)$ for $30 \mathrm{mins}$ in different $\mathrm{pH}$ conditions ( $\mathrm{pH} 1.2,6.0$ and 7.4) in PBS. Later, the samples in different $\mathrm{pH}$ were placed in shaking incubator at $37^{\circ} \mathrm{C}$, shaked gently for the predetermined time period where pGLP1 could be released for the nanocarrier. Samples were collected and EtBr $(0.1 \mathrm{mg} / \mathrm{mL})$ was mixed with different samples and the fluorescence was measured (Ex.520nm, Em.600nm) in 96 wells plate. The more DNA is released from the complex, the more it binds with $\mathrm{EtBr}$ and more fluorescence intensity is observed.

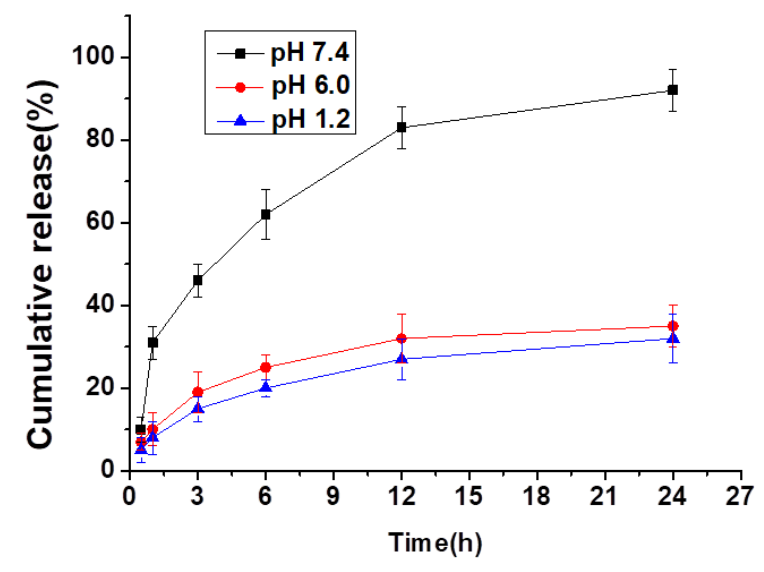

Figure S5. Cumulative release curve of pDNA in different $\mathbf{p H}$ condition. At $\mathrm{pH} 7.4$, the release of pDNA is significantly increased from the protamine-SMCC-Fc due to the weakning of electrostatic interaction between protamine and pDNA. Values are given as triplicates \pm SD. 
a

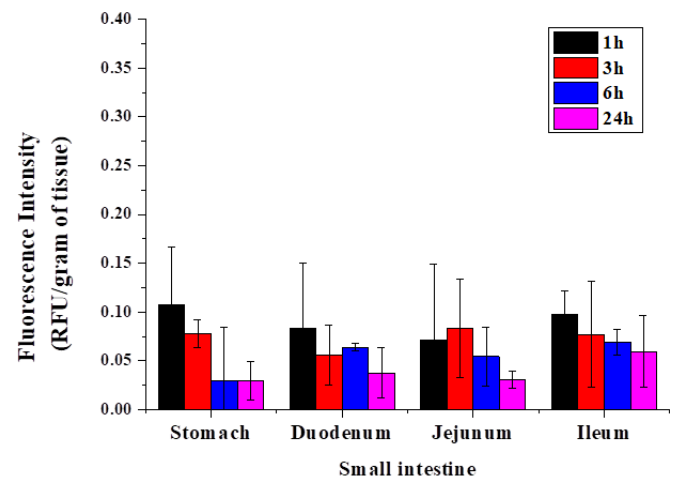

b

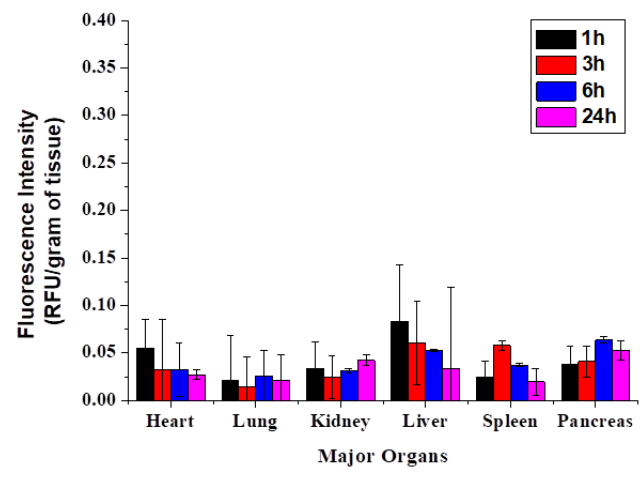

Figure S6. Biodistribution analysis of free rhodamine $B$ in $B a l b / C$ mice $(n=3)$. The fluorescence of free rhodamine distribution was analyzed in a) small intestine and b) major organs of the Balb/C mice as a control. 


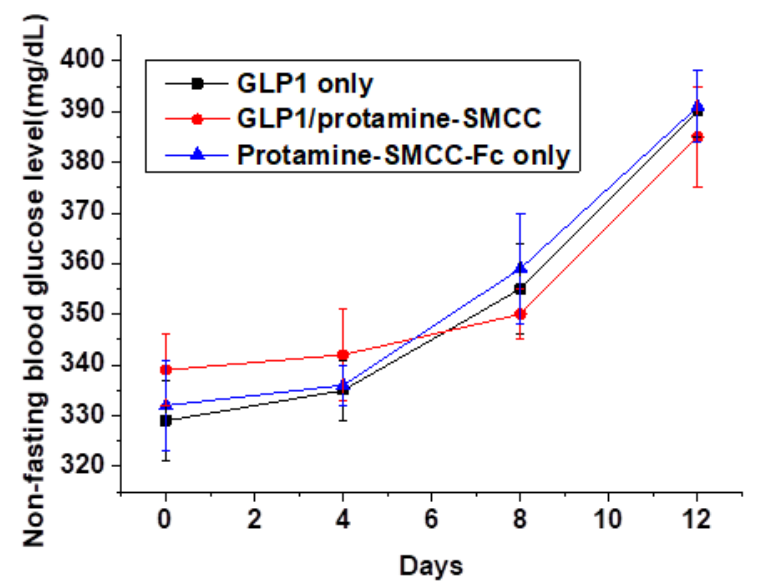

Figure S7. Anti-diabetic effect of additional control groups in diabetic mice. 


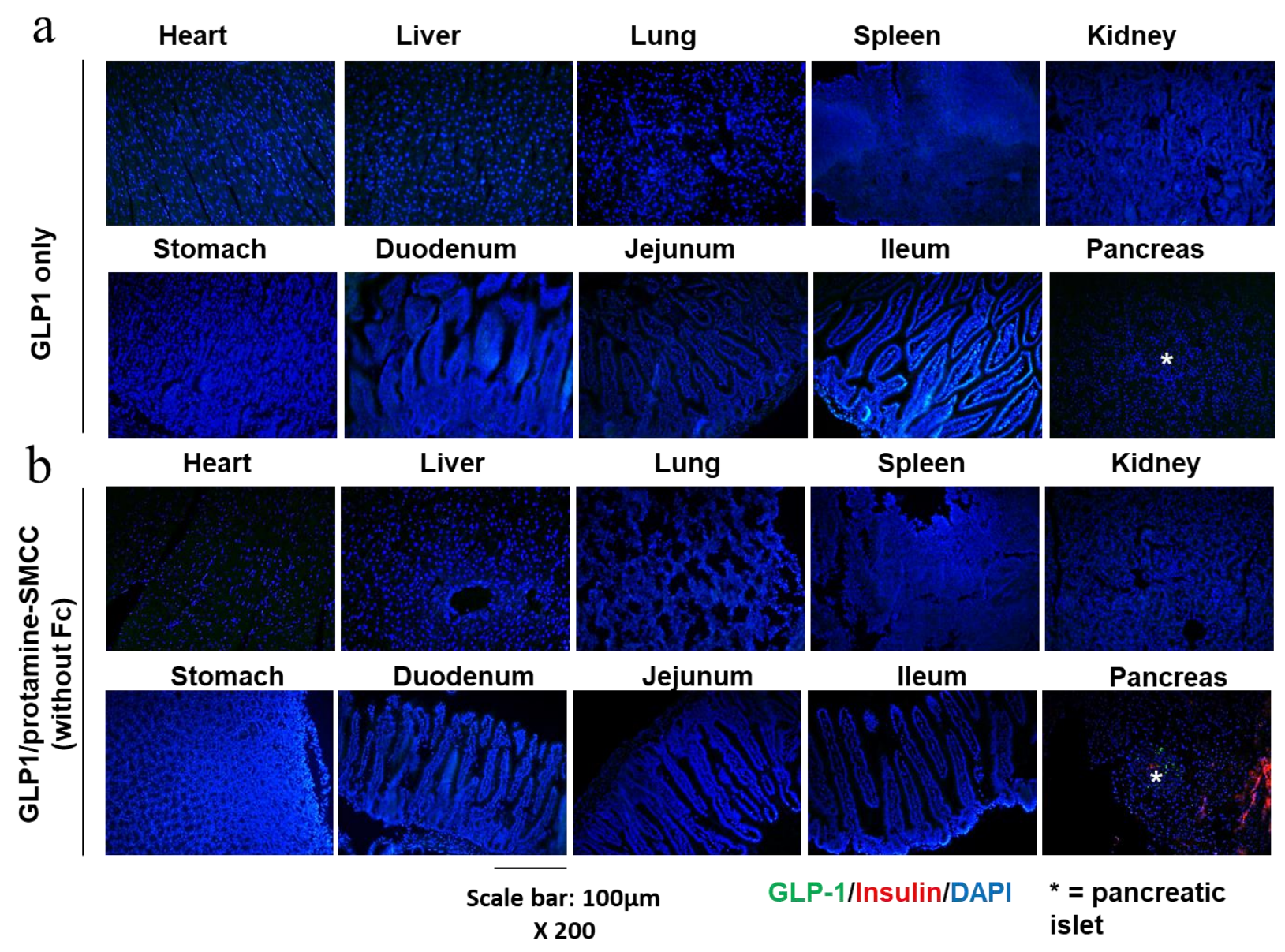

Figure S8. GLP1 and insulin expression after oral GLP1 gene delivery in control groups. Immunofluorescence (IF) staining for the GLP1 and insulin expression in various organs after PO administration of a) only GLP1 and b) 500 $\mu$ g GLP1/protamine-SMCC(without Fc modification). Rrepresentative images obtained from 5 mice in each group. ${ }^{*}$ pancreatic islet, Scale $=100 \mu \mathrm{m}$ 


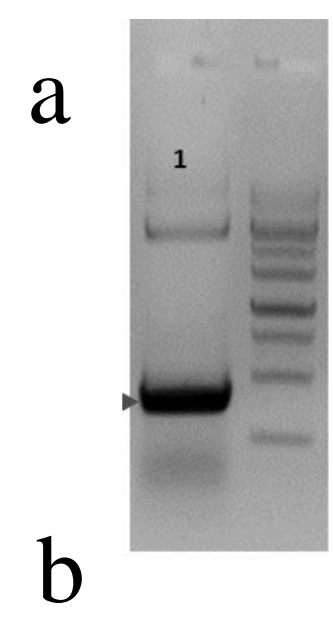

Lanes(Template: Avastin heavy chain)

1: Cys-Fc PCR (Annealing T : 58, 750bp

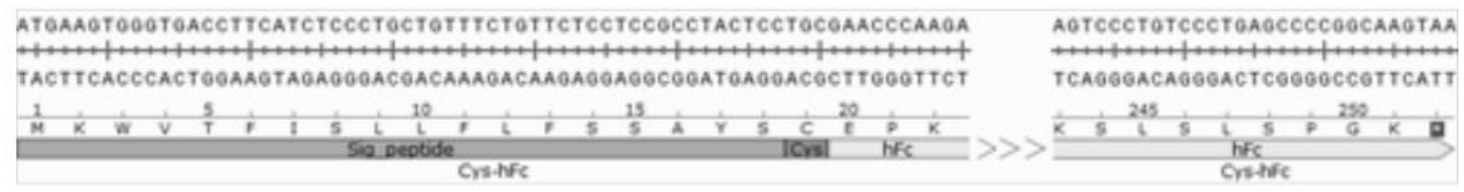

Figure S9. Preparation of hIgG1-Fc-Cys. a) N-terminal Cys extension of human IgG1-Fc by PCR. Lane 1. hIgG1-Fc-Cys PCR (annealing T: 58, 750 bp), next, Mw. DNA ladder. The template for PCR was an Avastin heavy chain. b) DNA sequence analysis of the hIgG1-Fc-Cys expression vector.

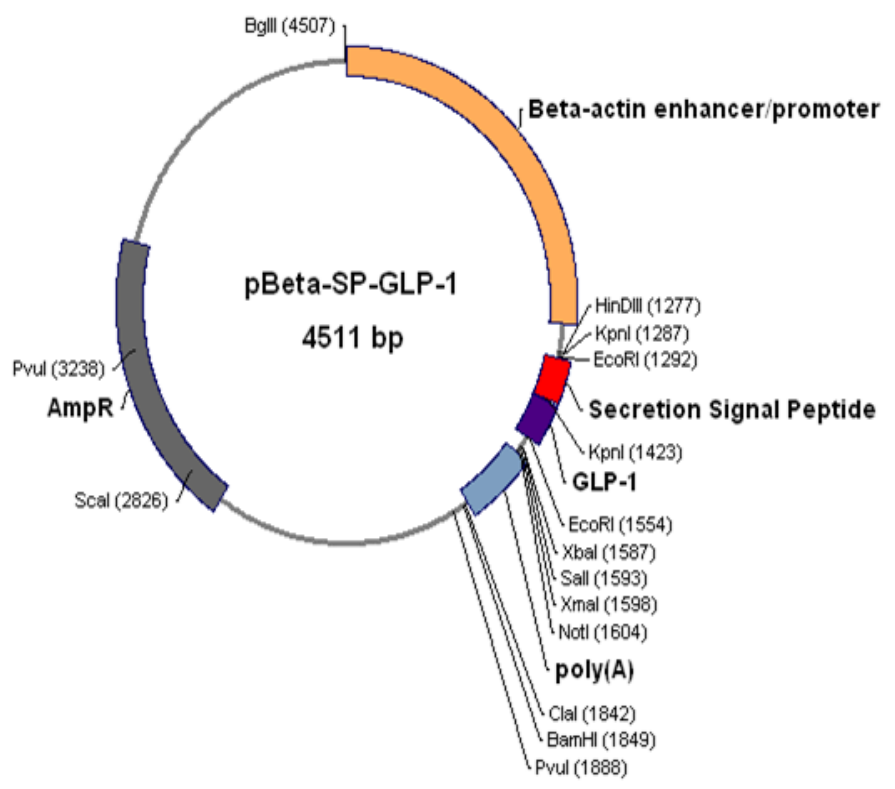

Figure S10. Plasmid vector of pBeta-SP-GLP-1. cDNA were encoded in the furin cleavage site, next to secretion signal peptide. 

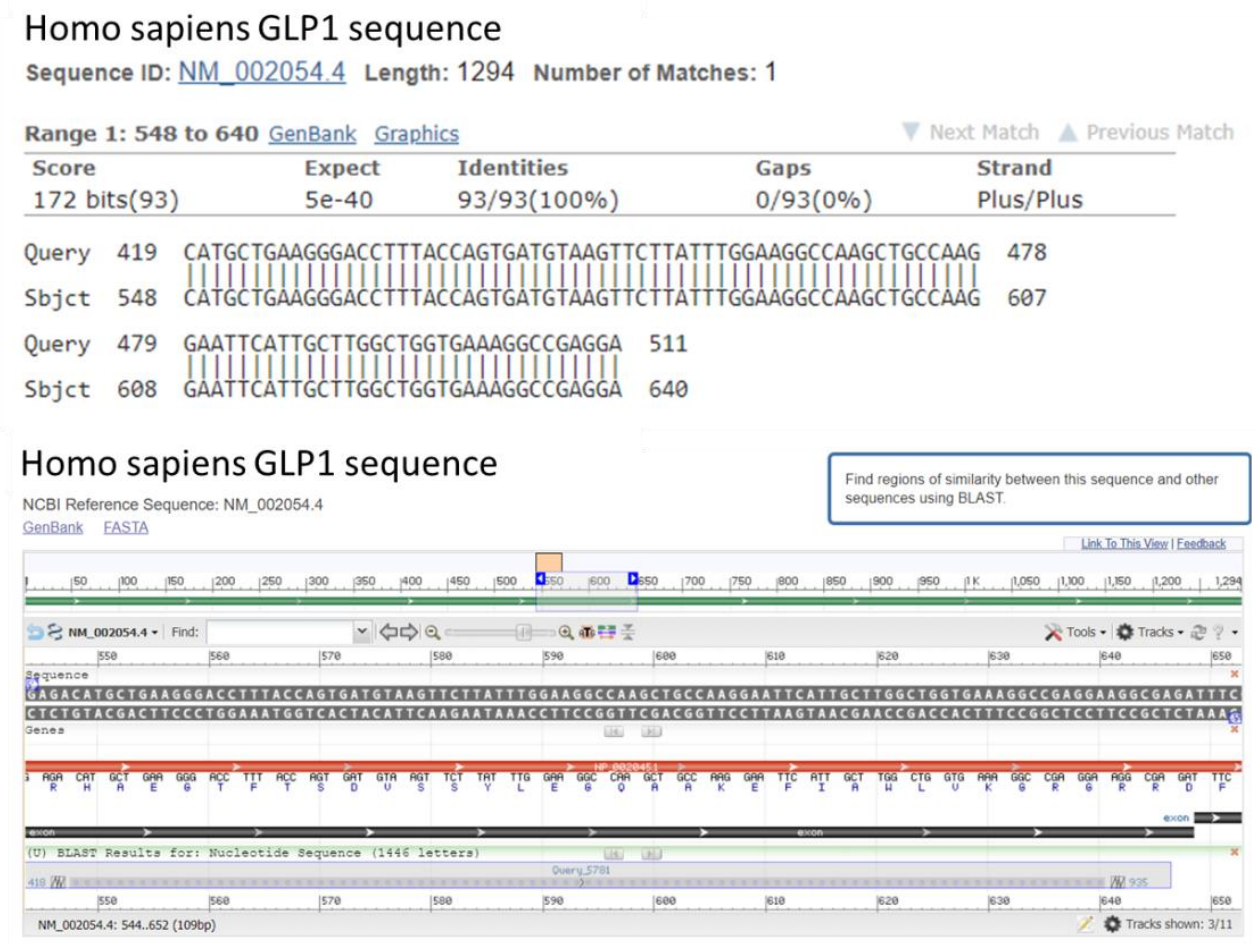

Figure S11. GLP1 sequence analysis and confirmation. Experimental GLP1 sequence was matched with the blast result from NCBI.

\section{In Vivo oral toxicity analysis}

Diabetic mice were tested for any toxicity effect after oral gavage of Protamine-SMCC-Fc carrier. The experiment was performed by Korea Testing \& Research Institute (KTR), 12-63, Sandan-gil, Hwasun-gun, Republic of Korea.

KTR performed a study of single-dose oral toxicity of the protamine-SMCC-Fc carrier with the 5 weeks old male and female CrIOri: CD1 (ICR) mice. $10 \mathrm{mg} / \mathrm{kg}$ body weight was set for the highest dose and $6.66 \mathrm{mg} / \mathrm{kg}$ body weight, and $3.33 \mathrm{mg} / \mathrm{kg}$ body weight was set for middle and low dose oral gavage. Mice were divided into four groups-control (no oral nanocarrier), $10 \mathrm{mg}$, $6.66 \mathrm{mg}$, and $3.33 \mathrm{mg}$ nanocarrier $/ \mathrm{kg}$ body weight of mice. Each group contained a subgroup of male and female mice with mice number, $n=5$. 
Table S1: Mortality

\begin{tabular}{|c|c|c|c|}
\hline Group & Dose(mg/kg body weight) & $\begin{array}{l}\text { Male } \\
\text { Female }\end{array}$ & \\
\hline G1 & 0 & $\begin{array}{c}0 \% \\
(0 / 5)^{\mathrm{a}}\end{array}$ & $\begin{array}{r}0 \% \\
(0 / 5)^{\mathrm{a}}\end{array}$ \\
\hline $\mathrm{G} 2$ & 3.33 & $\begin{array}{c}0 \% \\
(0 / 5)^{\mathrm{a}}\end{array}$ & $\begin{array}{r}0 \% \\
(0 / 5)^{\mathrm{a}}\end{array}$ \\
\hline G3 & 6.66 & $\begin{array}{c}0 \% \\
(0 / 5)^{\mathrm{a}}\end{array}$ & $\begin{array}{r}0 \% \\
(0 / 5)^{\mathrm{a}}\end{array}$ \\
\hline G4 & 10 & $\begin{array}{c}0 \% \\
(0 / 5)^{\mathrm{a}}\end{array}$ & $\begin{array}{r}0 \% \\
(0 / 5)^{\mathrm{a}}\end{array}$ \\
\hline
\end{tabular}

${ }^{\mathrm{a}}$ : Number of dead animals/Number of tested animals

Mortality, clinical signs, body weight, and necropsy findings were observed for 14 days after single oral administration. The following result had been obtained.

- No deaths occurred during the observation period.

- Clinical signs related to the test substance had not been observed in the animals during the observation period.

- In the body weight of animals, there were no significant variations in the test substance treated groups compared to the control group.

- In all animals, there were no abnormal necropsy findings caused by the administration of test substance. 